\title{
GRANDE SERTAO: VEREDAS, EN CHILE: RECEPCIÓN, GRADO CERO (UNA CRÓNICA)
}

Soledad Bianchi

Universidade do Chile

D e cómo se recibió y se leyó Gran Sertón: Veredas cuando en 1967, el volumen de Seix-Barral fue editado y llegó a Chile desde España, no hay mucho que decir pues casi son nulas las publicaciones periodísticas o académicas, contemporáneas a él, que registren y constaten su acogida. Con brevedad y sin complicaciones, yo podría llegar sólo hasta aquí, mas opto por prolongar este artículo pues quisiera notar y apuntar ciertos rasgos y a ciertos trazos para bosquejar una suerte de mapa de relaciones entre esta novela y aspectos que sin remitir linealmente a la recepción, creo que en distancias y cercanías, en contrastes, en contradicciones, en negativas, en "cegueras" y "sorderas", siguen refiriendo a ella, pero a partir de desvíos y en rodeos, cuyos resultados serán sólo esbozos y sugerencias.

En la Biblioteca Nacional, de Santiago de Chile, casi no encontré artículos sobre Gran Sertón: Veredas, en mi rastreo parcial de periódicos chilenos de 1967. Pero mi sorpresa aumentó cuando accedí a los viejos y poco frecuentados archivos del antiguo "Centro de Investigaciones de Literatura Comparada” , perteneciente a la Universidad de Chile desde su fundación, en 1956, hasta 1969, poco después de la Reforma Universitaria. Allí, los recortes de notas y reseñas referentes a Joao Guimaraes Rosa no sólo no eran tan escasos sino, además: la gran mayoría no había sido publicado en castellano... ni en Chile... A "tropezones", me enteré en esas páginas ya amarillentas, que como Grande Sertao había aparecido la novela en... Alemania, y en ... ii1964!!, y que era presentada como "Brasilianische Tropen-Saga" ["La saga brasileña tropical”] y como "Brasilianisches Epos” [“La epopeya brasileña”]. Me impuse, 
asimismo, que en ... ii1963!! había sido publicada en Estados Unidos con el título The Devil to pay in the Backlands -aproximadamente: Posibles Problemas en las Tierras Desiertas- y que en "Outlaw with a Problem", The New York Times Review Books la consideró casi como una película del oeste, opinión no tan singular si se repara que la importancia otorgada por el Herald Tribune-Books a sus personajes, lleva a nominar su reseña, "Cowboys and Gansters in Brazil's Badlands".

Como a modo de guías, los títulos obedecen siempre a una determinada perspectiva y a un énfasis para resaltar alguno(s) de los aspectos de las obras. Entonces, resulta interesante constatar cómo varían los nombres de las traducciones de una misma novela, en cada país o, más bien, en áreas de culturas similares, que las nominaciones -en sus diferencias- señalan. Así, en Francia, Grande Sertao: Veredas fue dada a conocer, en 1965, como Diadorim, apelativo del bello joven yagunzo por quien Riobaldo, el narrador, se sentía profundamente cautivado. De este modo, al lector se le enfoca hacia esta mutua atracción, fluctuante entre la amistad y el amor y su negativa: “...Me gustaba y no me gustaba. ...", afirma Riobaldo, vacilando. (Sin titubeos, yo abro un paréntesis para recoger y trasladar -"traducir (del lat[ín] "traducere", conducir al otro lado, pasar)", dice María Moliner- una distinción hecha por Walter Benjamin entre lo mentado y la manera cómo se mienta: “ “.. En "Brot" [pan] y "pain" [pan] -dice-, lo mentado es lo mismo, pero no la manera de hacerlo pues a causa de este modo de mentar, las dos palabras significan algo diferente en alemán y en francés; no son intercambiables e, incluso, finalmente, tienden a excluirse. En cambio, si consideramos lo mentado como absoluto, significan una sola y misma cosa; mientras que la manera de mentar está en oposición en estas dos palabras, ella se completa en las dos lenguas de donde provienen. De hecho, en ellas se completa la manera de mentar lo mentado. ...”. Y finalizo este extravío... de sentido).

\footnotetext{
La traducción del siguiente párrafo de Benjamin parece una muestra de su propia tesis ya que mientras la traducción francesa usa "viser": enfocar, mirar, y distingue entre "le visé" y "la manière de viser", y la inglesa alude al "objeto" y la "intención”, Pablo Oyarzún que sigue el original alemán-que yo no conozco y que si lo tuviera, desgraciadamente tampoco entenderíarefiere a "mentar", por el que opté en mi versión desde el francés.
} 
Retrocedo para señalar que el profesor y crítico literario Nelson Osorio, sospecha que hayan sido esas simpatías homosexuales una de las posibles causas del escaso interés de esta narración de Guimaraes, en Chile. Aunque yo no quisiera aceptar esta imagen tan disminuida y estrecha de cierto lector chileno, sería imposible negarme a ella si pienso que hasta no hace tanto, y con posterioridad al Golpe de Estado, el más determinante comentarista periodístico de libros en el medio chileno, fue el sacerdote del Opus Dei, José Miguel Ibáñez Langlois, quien como Ignacio Valente firmaba semana a semana en el diario, El Mercurio: en ocasiones, y obviando particularidades literarias, valoró y desaprobó drásticamente algunas obras por considerar que no se avenían a (sus) principios religiosos y eclesiales... Tampoco puedo desconocer el conservadurismo y los prejuicios que recorren la sociedad chilena, incluso hoy, pero no quisiera paralogizarme, y prefiero seguir preguntándome sobre la lectura de Gran Sertón: Veredas.

Buen año fue 1967 para la literatura escrita en español. Desde ese mayo, lectores de la América Hispana nos enredamos, extasiados, en el laberíntico linaje de los Buendía, de Cien años de soledad, del nombre de cuyo autor -estoy segura- no necesito acordarme. Esta narración de Gabriel García Márquez se agregaba a otras varias que con magia, incluso urbana (con La ciudad y los perros se inició Mario Vargas Llosa), exigían considerarlas "del lado de allá" de escritos anteriores que, con pocas excepciones, ya se volvían fatigosos por repetitivos: en estructura, en personajes, en espacio, en modos narrativos, en miradas... Cambio de piel, llamaba Carlos Fuentes a su novela aparecida ese mismo 1967, y sin aludir al texto y sus significaciones, y limitándonos a considerar este título al pie de la letra, podríamos verlo como una denominación adecuada para evidenciar el proceso que estaba sucediendo en mucha de la narrativa que se producía entonces, que en cantidad y diferencia iba tramando un complejo conjunto dispar y tan poco causal como los saltos y la (supuesta) libertad que el "Tablero de dirección” de Rayuela, pareció permitirnos cuando, en 1963, Julio Cortázar se propuso descentrar y multiplicar el centro y aflojar dicotomías y maniqueísmos, tan caros a Occidente, y nos hizo buscar "Del lado de allá", "Del lado de acá” y "De otros lados”, de Buenos Aires a París y viceversa, cada lugar invadiendo y volviéndose el otro, como cuando Horacio cree reconocer a la Maga en la capital argentina. 
Aceptando que no me convence demasiado, admito y continúo trabajando, aquí, con una convención y un rótulo, y reconozco que a una parte de esa producción literaria se le llamó "el boom de la novela latinoamericana" y hoy, a casi medio siglo de distancia, se le ve aún como paradigma, y continúa fijada con la misma etiqueta, aunque - ahora - se le considere con menos respeto $\mathrm{y}$, con frecuencia, se perciba como monumento inerte porque se olvida su contexto, tan diferente al actual que se hace casi incomprensible, como difíciles de entender las preocupaciones de ese ayer. Si indiscutible es la calidad de muchos de esos escritos, ni tampoco merece discusión la creatividad de sus autores, no hay que olvidar que, en sus inicios, el "boom" fue un fenómeno comercial, y editorial, cuyos primeros parámetros y segmentaciones no fueron dictados por la institución literaria: de ahí, esa suerte de 'santoral' decidido por jueces anónimos que, con criterios desconocidos, aceptaron y discriminaron, y decidieron sobre la entrada o la expulsión del "templo": ¿cómo entender, por ejemplo, las ausencias de Juan Rulfo, Elena Garro, José Emilio Pacheco o José Lezama Lima?; ¿por qué no haber considerado a Pedro Páramo, Los recuerdos del porvenir, Morirás lejos o Paradiso?

Todos esos autores aludidos - "integrantes" y/o "descartados" del "boom" - son oriundos de la América Hispana y escriben en castellano. Entonces, se exagera cuando se alude al "boom de la novela latinoamericana" porque, entre otros, se deja fuera a Brasil y, para ser precisos, la rúbrica debería limitar al "boom de la novela hispanoamericana”: “... Brasil está más desconectado con el resto de América Latina que con Europa o con los Estados Unidos..., decía Emir Rodríguez Monegal en su artículo, "La novela brasileña”, publicado en Mundo Nuevo, revista que él dirigía, en París. Varios de sus párrafos fueron reproducidos en la carta del 16 de marzo de 1967 que la Editorial Seix Barral enviaba a ciertos medios -algunos chilenos, entre ellos- desde Barcelona, junto a un ejemplar de la novela de Guimaraes, para promocionarla.

Este mismo confinamiento era el deslindado por los estudios universitarios de literatura, en la década del 60, en Chile -y hasta en más lugares, me temo-, cuando se evitaba tanto la literatura brasilera como aquélla en lenguas indígenas de la región. Y si algunas de esas reducciones académicas continúan en la actualidad, otras parecen haberse reparado: no obstante, nominar las manifestaciones indígenas como "literaturas pre-colombinas" o “pre-hispánicas”, incorpora una buena carga de subordinación y etnocentrismo. 
Frente al primer "olvido", Ángel Rama y Emir Rodríguez Monegal, dos críticos uruguayos notables, fueron claras excepciones, no sólo por su conocimiento del Brasil y su cultura sino, asimismo, por el relieve que les otorgaron siempre en sus estudios, de enfoques tan diversos: este interés trasciende y supera algunas explicaciones simplistas que lo reducen a una mecánica cercanía geográfica. De todos modos, es curioso que en esos años, apenas posteriores a la Revolución Cubana, cuando más se discutió sobre la identidad americana y cuando más interés hubo por una unidad abarcante y no sólo económica, como hoy -, en la práctica (cultural) se fragmentara, dejando de lado a buena parte del continente...

¿Por qué y para qué leer obras que no estén en su lengua original?, pueden haber discurrido algunos lectores hispanohablantes de ese tiempo cuando, además, en ese mismo momento e idioma se estaba produciendo una literatura cuantitativa y cualitativamente excepcional, y se tenía infinitas posibilidades de elección, y así se murmuraba y el secreto a voces se esparcía y publicitaba, minuto a minuto, de diario en revista, de reseña en artículo, de artículo en libro... Tanto más fácil, entonces, leer en castellano que acceder a Grande Sertao: Veredas, la compleja novela que Joao Guimaraes Rosa había publicado en 1956, en portugués, y que la Editorial Seix Barral - que también editaba a varios de los autores del "boom"- daba a conocer recién en 1967, "en lengua castellana” y "traducción española”, de Ángel Crespo, quien en una introductoria "Nota del Traductor" alude a su quehacer y a las dificultades con las que se enfrentó y las que encarará el lector: "El lenguaje de Guimaraes Rosa - dice no se ajusta, ni mucho menos, a las normas usuales de la lengua portuguesa, ni siquiera a las del portugués, matizado en muchos aspectos, que se escribe en el Brasil con la consideración de lengua culta o literaria...”. Y recalcando que él intentó conservar el "clima lingüístico del original", con las particularidades sintácticas y de lenguaje del estilo del escritor brasilero, se percata que los principales roces, - y hasta choques, diría yo -, para el receptor estarán relacionados con la puntuación, los neologismos, los arcaísmos, el "empleo impropio de ciertas palabras”, los cultismos, los localismos... Compleja resulta, sin duda, "La tarea del traductor", y así fue reconocido por Walter Benjamin:

... La libertad del traductor en su propia lengua, se afirma, más bien, en favor del lenguaje puro. Rescatar en su propia lengua este lenguaje puro 
exiliado en la lengua extranjera; liberar, transponiéndolo, este lenguaje puro cautivo en la obra: ésta es la tarea del traductor. En favor del lenguaje puro, hace saltar los marcos apolillados de su propia lengua: Lutero, Voss, Hölderlin y George ampliaron las fronteras del alemán [con sus traducciones]....

... toda traducción - dice Benjamin - sólo es un modo de alguna manera transitorio y provisorio de hacerse cargo de la ajenidad de las lenguas. Otra resolución de esta ajenidad que la temporera y provisional, una instantánea y definitiva, quédale negada al hombre, o en todo caso no cabe que aspire a ella - inmediatamente.

A mi entender, el resultado del trabajo de Ángel Crespo no tiene las limitaciones señaladas por el importante teórico de la traducción, Rudolf Pannwitz, recordado por Benjamin:

Incluso, nuestras mejores versiones [alemanas] parten de un falso principio pues quieren germanizar el sánscrito, el griego, el inglés, en lugar de sanscritizar, helenizar, anglicizar el alemán. Ellas respetan mucho más los usos de su propia lengua que el espíritu de la obra extranjera....

A causa de las dificultades lingüísticas, Crespo consideró imperioso cerrar Gran Sertón: Veredas con un “Glosario”, tal vez una necesidad, pero, asimismo, un fastidio que, además, evoca muchos escritos hispanoamericanos de antaño y su dejo regional y naturalista, ya superado, en buena parte por la labor de los escritores que se aproximaron, pertenecieron o debieron pertenecer al "boom". Todo lo anterior, moderaba, sin duda, hasta la mejor disposición a la lectura... Es necesario reconocer, también, que aparte sus logros, la novela es lenta y se hace monótona por su estructura y por su invariable modo narrativo, un monólogo vocalizado de un solo narrador, Riobaldo, quien cuenta y cuenta, incansable y ágilmente (tan rápido, a veces, que podría parecer 'monólogo de conciencia', si no supiéramos que, en voz alta, se dirige a un interlocutor), sus múltiples historias, llenando más de cuatrocientas páginas que podrían haberse reducido, pensamos, en cerca de un centenar. Este exceso lo hacen notar algunas de las escasas cuatro (4) críticas, encontradas en distintos periódicos chilenos, tres de las cuales se publicaron a causa de la muerte del escritor, el mismo 1967, fecha utilizada como subterfugio para comentar 
la novela por primera vez, valorando, especialmente, la proximidad de su lenguaje con la poesía.

Y es efectivo que uno de los aspectos más logrados es cómo el narrador fricciona el lenguaje, moldeándolo a su amaño, y con una libertad y "desfachatez" lingüísticas que se vuelven rasgos particulares de esta obra, y que se extienden también a la materia narrativa, constantemente aludida en una reiterada reflexión sobre la novela misma, su escritura, el modo en que se cuenta y se dice: “... . Contar es muy, muy dificultoso. ...”, repite Riobaldo, con su insistencia habitual. Iterativas son, asimismo, las preguntas sobre la identidad, sobre diversas identidades, no sólo personal, no sólo local. Porque hay mucho de ambigüedad en un relato donde afirmaciones y negaciones se suceden y contradicen, sin anularse y permaneciendo como en suspenso: “... A usted le parece y no le parece. Todo es y no es. ...”.

"... Ah, el tiempo del yagunzo tenía que acabarse, la ciudad acaba con el sertón. ¿Acaba?”, dice Riobaldo refiriendo a un mundo que está variando por la llegada de la modernidad, pero la innovación, el cambio, las alteraciones, las metamorfosis, no son sólo un tema y en una búsqueda constante de modos de decir, de formas, de léxico, la expresión se acomoda y se engarzan lo que se dice y el modo cómo se dice.

Y así, movilidades y fluctuaciones son definitorias de Gran Sertón: Veredas... Como Jefe del Departamento de Fronteras, Joao Guimaraes Rosa debía hacerlas respetar. No obstante, con su escritura quebró y burló fronteras lingüísticas, sintácticas, temáticas, genéricas... Partiendo de esta productiva afirmación de Marli Fantini Scarpelli, ${ }^{2}$ imagino que estos cruces y rupturas podrían explicar la poca recepción que la novela tuvo, en Chile, por lo menos, en la década del 60.

Santiago, enero del 2002. 


\section{BIBLIOGRAFÍA}

\section{1.- Bibliografía Activa}

\section{Obra de Joao Guimaraes Rosa}

Gran Sertón: Veredas. Traducción de Ángel Crespo. Barcelona, Editorial Seix Barral, 1967. (Biblioteca Formentor).

\section{Artículos Periodísticos (sobre Gran Sertón: Veredas)}

BERGIN, Thomas G.: “Cowboys and Gansters in Brazil's Badlands”, en Herald TribuneBooks (i?, 19 mayo 1963).

CALDERÓN, Alfonso: “Aprendizaje del miedo”, en Ercilla 1694 (Santiago de Chile, 6 diciembre 1967).

Carta de Editorial Seix Barral. Circular a mimeógrafo. Barcelona, 16 marzo 1967.

DÉLANO, Luis Enrique: “Joao Guimaraes Rosa”, en La Última Hora (Santiago, 4 diciembre 1967).

FLUSSER, Vilém: “Guimaraes Rosa oder: Das Grosse Hinterland des Geistes”, en Merkur 204 (i? , marzo 1965).

GROSSMAN, William L.: "Outlaw with a Problem", en The New York Times Review Books (Nueva York, 21 abril 1963).

HORST, Karl August. “Brasilianisches Epos”, en Frankfurter Allgemeine Zeitung (Frankfurt, 27 octubre 1964).

JOHNSON, Harvey L.: "The Evil one Led the Bands", en Saturday Review (¿?, 1ำ junio 1963).

KROLOW, Karl: "Brasilianische Tropen-Saga”, en SüdDeutsche Zeitung (¿?, 17 septiembre 1964).

LACHGAR, Lina: Diadorim, par Joao Guimaraes Rosa. Trad.du brésilien par Jean-Jacques Villard”, en Livres de France (París, juin-juillet 1965).

LORENZ, Günter W.: "Eine Welt in ihrem Urzustand", en Die Welt (i?, 17 septiembre 1964).

MICHELOUD, Pierrette: Diadorim, par Joao Guimaraes Rosa”, en Les Nouvelles Littéraires (París, 22 julio 1965).

N.N.: “Gran Sertón. Veredas, por Joao Guimaraes Rosa. .. [datos bibliográficos]”, en Plan 18 (Santiago, octubre 1967).

NEMO: “Requiem para un brasileño", sección: “Desde nuestro aislamiento", en PEC 260 (Santiago, 22 diciembre 1967). 
REITZ, Hellmuth: Rosa, Joao Guimaraes: Grande Sertao... [datos bibliográficos], en Welt und Wort (Tübingen, marzo 1965).

\section{Bibliografía Adicional}

BENJAMIN, Walter: "La tâche du traducteur", en I. Mythe et violence. Essai. Traduit de l'allemand et préfacé par Maurice de Gandillac. Evreux, Denoël, 1971, 261-275.

OYARZÚN, Pablo: “Sobre el concepto benjaminiano de traducción”. Separata de Seminarios de Filosofía №6 (1993), 67-101. (De aquí tomé la definición de WB sobre traducción).

\section{2.- Bibliografía Pasiva}

BRION, Marcel: “Un autre monde, Litterature sud- americaine”, en Les Nouvelles littéraires (París, 11 enero 1962). [Parcialmente, sobre Buriti, recopilación de tres cuentos de Guilaraes [sic] que "por su atmósfera podrían ser uno", y sobre tres narraciones de otros autores].

- : “Invitations au voyage. Roman sud-américaines”, en Les Nouvelles Littéraires (París, 13 diciembre 1962). [Dedicado, en parte, a Les Nuits du Sertao, novela traducida con este título, perteneciente a un ciclo, cuyo primer volumen editado, en Francia, fue Buriti].

BRUNET, Ch.: “Buriti, par Joao Guimaraes Rosa”, en Les Nouvelles Littéraires (París, 15 junio 1961). [Sobre Buriti].

COLEMAN; Alexander: "Thinking Beast", en The New York Times Book Review (Nueva York, 17 abril 1966). [Sobre_Sagarana].

DEL SOLAR, Hernán: “Guimaraes Rosa: “Primeras Historias”, en El Mercurio (Santiago, 3 agosto 1969). [Sobre Primeras Historias].

FREUSTIE, Jean: "Littérature équatoriale", en France Observateur (i?, 18 octubre 1962). [Sobre Les Nuits du Sertao, enfocado con un dejo de superioridad e ironía].

GUIMARAES ROSA; Joao: "La tercera orilla del río”. Cuento, en Espiral (Bogotá, marzo 1966).

- : “Der Teufel im Wirbelwind”, en Merkur 193 (i?, marzo 1964).

HAUBRICH, Walter: "Wenn nichts geschieht, geschieht ein Wunder", en Frankfurter Allgemeine Zeitung (Frankfurt, 7 enero 1967). [Sobre: Corpo de baile].

J.B.: "Les nuits du sertao, par Joao Guimaraes Rosa”, en Les Nouvelles Littéraires (París, 3 enero 1963). [Sobre la novela traducida con este título]. 